\title{
Elektrokoagülasyon Prosesi Kullanılarak Mezbaha Atıksularının Arıtımı Üzerine Ortam Parametrelerinin Etkisi
}

\author{
Mehtap Tanyol $^{1 *}$, Servet Tevkur ${ }^{2}$ \\ I*Munzur Üniversitesi, İktisadi ve İdari Bilimler Fakültesi, Siyaset Bilimi ve Kamu Yönetimi Bölümü, Kentleşme ve \\ Çevre Sorunları Anabilim Dalı, Tunceli, Türkiye \\ ${ }^{2}$ Munzur Üniversitesi, Çevre Mühendisliği Anabilim Dall, Tunceli, Türkiye \\ *mtanyol@munzur.edu.tr $\mathrm{D}$, Servettevkur@hotmail.com $\mathrm{D}$, \\ Makale gönderme tarihi: 11.09.2020, Makale kabul tarihi: 08.12.2020
}

\begin{abstract}
$\ddot{O} z$
Mevcut çalışmada, mezbaha atıksuyunun arıtımı üzerine elektrokoagülasyon prosesinin etkinliği kesikli bir reaktör kullanılarak araştırılmıştır. Akım yoğunluğu (5-20 mA m²), başlangıç pH'ı (3-10) ve elektrotlar arası mesafe (4-16 mm) gibi çeşitli parametrelerin etkisi optimum elektrokoagülasyon koşulunu belirlemek için incelenmiştir. Paralel bağlanmış monopolar demir elektrotlar tüm deneyler için kullanılmıştır. Deneylerin performansı temel olarak kimyasal oksijen ihtiyacı (KOI) giderimi kullanılarak değerlendirilmiştir. 15 mA m² akım yoğunluğu, doğal pH (7.47) ve 16 mm elektrotlar arası mesafe optimum koşullar olarak seçilmiştir. Bu koşullar altında \%90.63'lük KOİ giderim verimi elde edilmiştir. Sistemin işletme maliyeti, enerji ve elektrot tüketimi dikkate alınarak hesaplanmış ve $9.15 \mathrm{TL} \mathrm{kg}^{-1} \mathrm{KOI}^{-1} \mathrm{olarak}_{\text {bulunmuştur. }}$
\end{abstract}

Anahtar kelimeler: Demir elektrot, elektrokoagülasyon, mezbaha atıksuları

\section{Effect of Medium Parameters on Treatment of Slaughterhouse Wastewater Using Electrocoagulation Process}

\begin{abstract}
In the present study, the efficiency of the electrocoagulation process on the treatment of slaughterhouse wastewater was investigated using a batch reactor. The effect of several parameters such as current density $\left(5-20 \mathrm{~mA} \mathrm{~m}{ }^{-2}\right)$, initial pH (3-10), and distance between electrodes (4-16 mm) was investigated to determine the optimum electrocoagulation condition. Parallel-connected monopolar iron electrodes were used for all experiments. The performance of the experiments was mainly evaluated using the chemical oxygen demand (COD) removal. The optimum conditions were selected as $15 \mathrm{~mA} \mathrm{~m}^{-2}$ current density, natural $\mathrm{pH}$ (7.47), and $16 \mathrm{~mm}$ distance between electrodes. Under these conditions a COD removal efficiency of $90.63 \%$ was achieved. The operating cost of the process was calculated taking into account the energy and electrode consumption and found to be $9.15 \mathrm{TL} \mathrm{kg}^{-1} \mathrm{COD}^{-1}$.
\end{abstract}

Keywords: Iron electrode, Electrocoagulation, slaughterhouse wastewaters

\section{GİRIŞ}

Et, insanların temel tüketim maddelerinden biri olduğu için mezbahalar yaygın bir endüstri dalıdır. Son yıllarda et tüketimi hizlanarak artmaya devam etmektedir. Mezbaha sektörü, hayvanların kesilmesi ve mezbaha fabrikalarının temizlenmesi nedeniyle hem üretim hem de üretim dişı birimlerden önemli miktarda atıksu üretmektedir (Rajakumar ve ark., 2012). Mezbaha atıksuları, Amerika Birleşik Devletleri Çevre Koruma Ajansı (USEPA) tarafindan en tehlikeli atıksulardan biri olarak sinıflandırılmaktadır (Alfonso-Muniozguren ve ark., 2020). Atıksu, askıda katı maddeler ve yağ, kan, protein ve selüloz gibi koloidal maddeler nedeniyle biyokimyasal oksijen ihtiyacı (BOI) ve kimyasal oksijen ihtiyacı (KOI), azot, fosfor, yağ ve gres gibi önemli biyolojik olarak parçalanabilir organik bileşikler içermektedir. Ayrıca bu atıksular, patojenik ve patojenik olmayan mikroorganizmalar, deterjanlar, antibiyotikler, aşılar ve diğer farmasötikler nedeniyle eser miktarda ilaç kalıntıları içermektedir.

$\mathrm{Bu}$ atıksular arıtılmadan alıcı ortama deşarj edilirse çözünmüş oksijen seviyesini azaltabilir ve dolayısıyla biyolojik yaşamı olumsuz etkileyebilir. $\mathrm{Bu}$ nedenle sucul ortama deşarj edilmeden önce 
atıksuyun arıtılması gereklidir (Öztürk ve Yılmaz, 2019).

Genellikle mezbaha atıksularının arıtımı için, aktif çamur, stabilizasyon havuzları, anaerobik reaktörler ve kombine prosesler gibi biyolojik prosesler kullanır. Bu prosesler başarılı olsalar da, genellikle uzun hidrolik alıkoyma süresi ve geniş alanlar gerektirirler. Aynı zamanda fazla miktarlarda çamur oluştururlar. Ayrıca mezbaha atıksuları zararlı ve biyolojik olarak parçalanamayan organik maddelerde içerebildiğinden biyolojik arıtma yetersiz olabilir. Elektrokoagülasyon, atıksu arıtma sistemleri için alternatif bir teknolojidir ve inorganik ve organik kirleticileri ve patojenleri gidermede oldukça etkilidir. Geleneksel kimyasal pıhtılaşma ile karşılaştırıldığında elektrokoagülasyon, basit ekipman, kolay işletme ve otomasyon, kısa alıkoyma süresi, düşük çamur üretimi ve kimyasal gerektirmemesi gibi birçok avantaja sahiptir. Mezbaha atıksuları genellikle kan içerdiğinden kandaki iyonlar ve elektrolitler elektriksel iletkenliği indüklemektedir. $\mathrm{Bu}$ mezbaha atıksularının elektrokimyasal işlemlerle arıtılmasını avantajlı hale getirmektedir (Daneshvar ve ark., 2007; Nery ve ark., 2007; Öztürk ve Y1lmaz, 2019). Elektrokoagülasyon, ortama bir elektrik akımı uygulayarak sulu bir ortamda süspansiyon haline getirilmiş, emülsifiye edilmiş veya çözünmüş kirleticileri destabilize etme işlemidir (Bayar ve ark., 2011). Elektrokoagülasyon prosesi aşağıda verildiği gibi kurban anotlar kullanılarak atıksuda elektrokimyasal olarak $\mathrm{M}^{+3}$ iyonlarının yerinde üretilmesinden oluşur.

$$
\text { anot: } \mathrm{M} \rightarrow \mathrm{M}^{+3} \text { (suda) }+3 \mathrm{e}^{-}
$$

Burada M genellikle demir (Fe) veya alüminyum (Al)'dur. Hidrojen gazı, anot olarak kurban malzemeden veya paslanmaz çelik gibi inert bir malzemeden yapılan katotta salınır.

$$
\text { katot: } 3 \mathrm{H}_{2} \mathrm{O}+3 \mathrm{e}^{-} \rightarrow 3 / 2 \mathrm{H}_{2}+3 \mathrm{OH}^{-}
$$

Kurban elektrotlar ayrıca asidik ortamda $\mathrm{H}^{+}$ iyonlar1 ile veya alkali ortamda $\mathrm{OH}^{-}$iyonları ile kimyasal olarak aşındırılabilir. Elektrot reaksiyonlar1 (1) ve (2) ile üretilen $\mathrm{M}^{+3}$ (suda) ve $\mathrm{OH}^{-}$ iyonları, $\mathrm{pH}$ aralığına bağlı olarak çeşitli hidrokso monomerik ve polimerik türler oluşturmak için reaksiyona girerler ve sonunda kompleks çökelme kinetiklerine göre $\mathrm{M}(\mathrm{OH})_{3}$ 'e dönüşürler. Yeni oluşmuş amorf $\mathrm{M}(\mathrm{OH})_{3}$ "süpürme flokları", çözünür organik bileşiklerin hızlı adsorpsiyonu ve kolloidal partiküllerin yakalanması için faydalı olan geniş yüzey alanlarına sahiptir. $\mathrm{Bu}$ floklar ayrıca $\mathrm{M}_{n}(\mathrm{OH})_{3 n}$ olarak polimerize olurlar ve hidrojen gaz1 ile sedimantasyon ve/veya flotasyon yoluyla sulu ortamdan kolayca giderilirler (Bayramoglu ve ark., 2006).

$\mathrm{Bu}$ çalışmada elektrokoagülasyon prosesi kullanılarak mezbaha atıksularından KOİ giderimi üzerine $\mathrm{pH}$, akım yoğunluğu, elektrotlar arası mesafe gibi farkl1 parametrelerin etkisi araştırılmıştır.

\section{MATERYAL VE METOT \\ Atıksu Temini ve Karakterizasyonu}

Çalışmada kullanılan mezbaha atıksuyu Tunceli'de bulunan Dersim Et Mezbaha ve Karkas Et Üretim Tesisinden (coğrafi koordinatları: $38^{\circ} 57^{\prime} 36.9^{\prime \prime} \mathrm{N} 39^{\circ} 34^{\prime} 14.0^{\prime \prime E}$ ) Ocak 2018'de 2 saatlik kompozit numune olacak şekilde temin edilmiştir. Tesis günlük olarak 500 küçükbaş ve 100 büyükbaş hayvan kesimi yapma kapasitesine sahiptir. Atıksuda yapılan analizler standart metotlara göre yapılmıştır (APHA, 2005) ve kullanılan metotlar şunlardır: KOİ, $5220 \mathrm{D}$; yağ ve gres, $5520 \mathrm{~B}$; toplam katı madde (TKM), $2540 \mathrm{~B}$; uçucu katı madde (UKM), $2540 \mathrm{~B} ; \mathrm{NH}_{3}-\mathrm{N}, 4500-\mathrm{NH}_{3} \mathrm{~F} ; \mathrm{NO}_{3}{ }^{-} \mathrm{N}$, $4500-\mathrm{NO}_{3}^{-} \mathrm{B} ; \mathrm{NO}_{2}^{-}-\mathrm{N}, \quad 4500-\mathrm{NO}_{2}^{-} \mathrm{B} ;$ toplam kjeldahl azotu (TKN), $4500 \mathrm{~N}_{\text {org }} \mathrm{B}$; $\mathrm{PO}_{4}^{-3}, 4500-\mathrm{P}$ C; bulanıklık $2130 \mathrm{~B}$, renk 2120 C. pH, iletkenlik ve toplam çözünmüş katı madde (TDS) değerleri multiparametre cihazı (YSI Pro Plus) kullanılarak numune alınırken yerinde ölçülmüştür.

\section{Deneysel Düzenek}

Mezbaha atıksuyunun arıtımında kullanılan elektrokoagülasyon reaktörü Şekil 1'de gösterilmiştir. Deneysel çalışmada kullanılan reaksiyon hücresi $1 \mathrm{~L}$ etkili hacme sahip pleksiglas malzemeden üretilmiştir ve $180 \mathrm{~mm}$ uzunluk, 170 $\mathrm{mm}$ genişlik ve $110 \mathrm{~mm}$ yüksekliğe sahiptir. Her bir deneyde $500 \mathrm{~mL}$ atıksu kullanılmıştır. $50 \mathrm{~mm} \times 80$ $\mathrm{mm}$ boyutuna sahip demir plakalar anot ve katot olarak reaktöre yerleştirilmiştir. Elektrotlar, akım için 0-3 A ve voltaj için 0-30 V aralıklarında çalışan bir dijital DC kaynağına monopolar-paralel şekilde 
bağlanmıştır. Deneyler sabit sıcaklıkta $\left(25{ }^{\circ} \mathrm{C}\right) 60$ dakikalık bir arıtım süresinde gerçekleştirilmiştir. Sıcaklığı sabit tutabilmek için reaksiyon hücresi su ceketli olarak yapılmıştır. Atıksuyun karışmasını sağlamak için deney sürecince sabit karıștırıcı kullanılarak atıksu 200 rpm'de karıștırılmıştır. Her deney çalışmasından sonra, kullanılan demir elektrotlar 10 dakika boyunca $0.25 \quad \mathrm{M} \quad \mathrm{H}_{2} \mathrm{SO}_{4}$ çözeltisine daldırılmıştır ve deiyonize su ile durulanmıştır. Atıksuyun pH'1 $0.1 \mathrm{M} \mathrm{HCl}$ ve $0.1 \mathrm{M}$ $\mathrm{NaOH}$ çözeltileri kullanılarak ayarlanmıştır. Elektrokoagülasyon prosesi süresince zamana bağlı olarak peristaltik pompa ile alınan örnekler 45 dakika doğal çökelmeye bırakılmıştır ve üstte kalan durusu 5000 rpm'de 5 dakika santrifüjlenerek analizlerde kullanılmıştır.

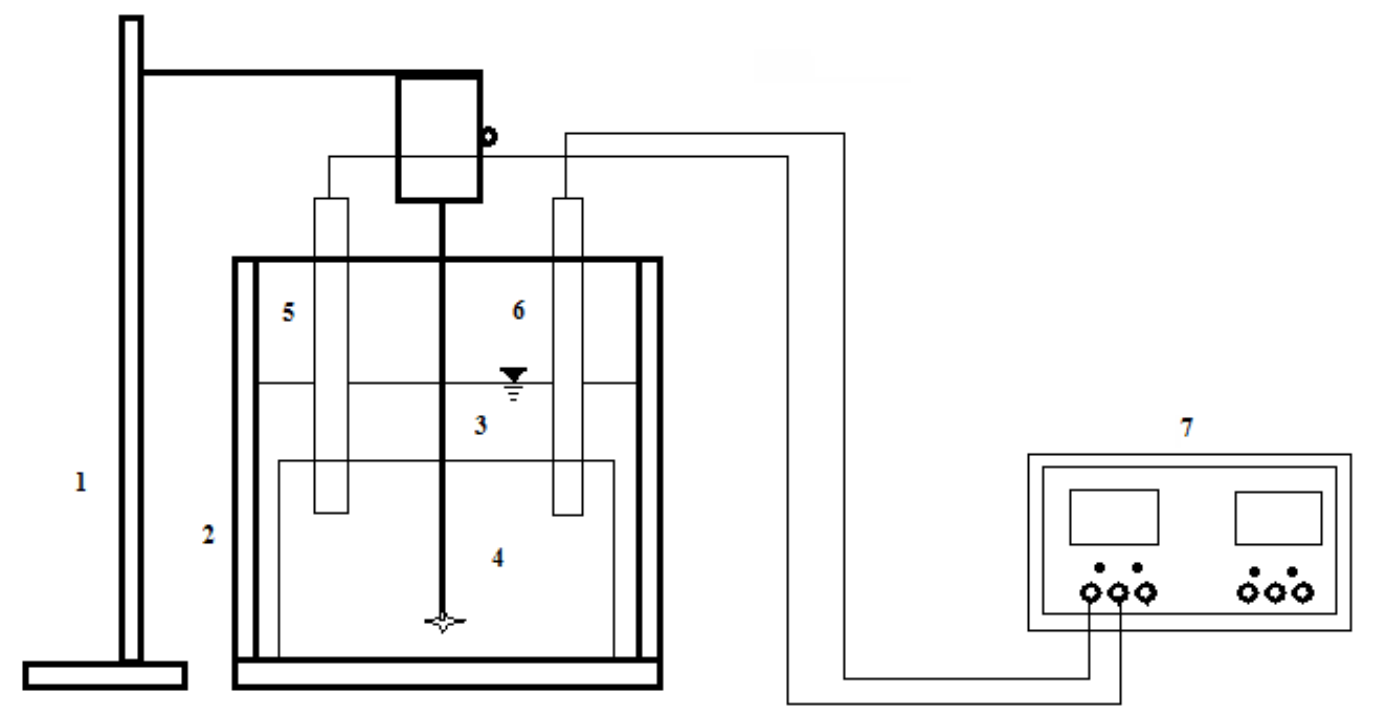

Şekil 1. Deneysel dizayn (1: mekanik karıştırıcı, 2: su ceketi, 3: elektrokoagülasyon reaktörü, 4: sabitleme plakası, 5: katot, 6: anot, 7: DC güç kaynağ1)

\section{İşletme Maliyeti}

Genel olarak, enerji tüketimi aşağıdaki formül ile hesaplanabilir (Tevkur, 2019):

$$
\mathrm{E}=\mathrm{U} x \mathrm{I} x \mathrm{t}
$$

Burada, E tüketilen elektrik enerjisi (kWh), U hücre potansiyeli (volt), I akım (A) ve t zamandır (sa).

Elektrokoagülasyon prosesinin verimliliği $(\Phi)$ aşağıdaki denklemle hesaplanmıştır (Tevkur, 2019):

$$
\Phi=\left[\frac{\Delta \mathrm{m}_{\text {deneysel }}}{\Delta \mathrm{m}_{\text {teorik }}}\right] \times 100
$$

Burada, $\Delta \mathrm{m}_{\text {deneysel }}$ elektrokoagülasyon ișlemi sırasında elektrotların deneysel ağırlık kaybının karşılaştırılmasına dayanır. Ayrıca, $\Delta \mathrm{m}_{\text {teorik }}$ elektroliz hücresinde indüklenen akımla çözeltide çözünen teorik metal çözünme miktarıdır ve Faraday yasasına göre hesaplanmıştır (Tevkur, 2019):

$$
\mathrm{M}_{\mathrm{teorik}}=\frac{\mathrm{M}_{\mathrm{w}} x \mathrm{I} x \mathrm{t}}{\mathrm{z}_{\mathrm{Fe}} x \mathrm{~F}}
$$

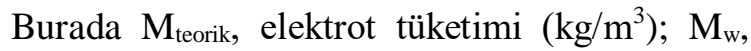
demirin moleküler kütlesi $(55,85 \mathrm{~g} / \mathrm{mol}) ; \mathrm{Z}_{\mathrm{Fe}}$, aktarılan elektron sayıs1 $\left(\mathrm{z}_{\mathrm{Fe}}=2\right)$ ve $\mathrm{F}$ Faraday sabitidir $(96485 \mathrm{C} / \mathrm{mol})$.

Elektrokoagülasyon prosesinin işletme maliyeti aşağıda verilen eşitlik kullanılarak hesaplanmıştır.

$$
\text { İşletme Maliyeti }=a \mathrm{C}_{\text {enerji }}+b \mathrm{C}_{\text {elektrot }}
$$

Burada, $a$, elektrik birim fiyatı (Aralık ayı 2018 y1lı için $0.4612 \mathrm{TL} \mathrm{kWh}^{-1}$ ) ve $b$, demir elektrot fiyatı (Aralık ayı 2018 yılı için $11.56 \mathrm{TL} \mathrm{kg}^{-1}$ )'dır.

$\mathrm{C}_{\text {enerji }}$ ve $\mathrm{C}_{\text {elektrot }}$ ise aşağıdaki eşitlikler kullanılarak hesaplanmıştır (Canizares ve ark., 2008; Palahouane ve ark., 2015; Tevkur, 2019): 


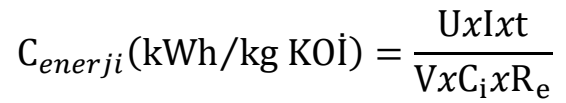

$$
\begin{aligned}
& \mathrm{C}_{\text {elektrot }}(\mathrm{kg} / \mathrm{kg} \text { KOI })=\frac{\mathrm{I} x \mathrm{t} x \mathrm{M}_{\mathrm{w}} x \Phi}{\mathrm{z}_{F e} x \mathrm{~F} x \mathrm{~V}_{\mathrm{i}} x \mathrm{R}_{\mathrm{e}}}
\end{aligned}
$$

Burada, V, atıksuyun hacmi $\left(\mathrm{m}^{3}\right) ; \mathrm{C}_{\mathrm{i}}$, giriș atıksuyunun KOİ konsantrasyonu $\left(\mathrm{kg} \mathrm{m}^{-3}\right)$ ve $\mathrm{R}_{e}$, KOİ giderim verimidir.

\section{BULGULAR VE TARTIŞMA \\ Akım Yoğunluğunun Etkisi}

Uygulanan akım ve dolayısıyla akım yoğunluğu, tüm elektrokimyasal sistemlerde en etkili parametrelerden biridir.

Elektrokoagülasyon prosesi boyunca hidrojen kabarcıklarının oluşma oranını ve flok büyümesini belirleyen akım yoğunluğu, koagülant türlerini oluşturmak üzere elektrot çözünmesini arttırmak için kullanılır (Fajardo ve ark., 2015).

Uygulanan akım yoğunluğunun KOİ giderimi üzerindeki etkisini test etmek için, doğal pH (7.47), $25{ }^{\circ} \mathrm{C}$ sicaklık ve $16 \mathrm{~mm}$ elektrotlar arası mesafede dört farklı akım yoğunluğu uygulanarak deneyler yapılmıştır ve sonuçlar Şekil 2'de gösterilmiştir.

Şekilden de görüldüğü gibi KOİ giderim hızı ilk 10 dakika içerisinde hızla artmıştır ve bundan sonra desorpsiyon nedeniyle KOİ giderim hızı azalmıştır (Safwat, 2020).

Akım yoğunluğunun $15 \quad \mathrm{~mA} \quad \mathrm{~m}^{-2}$ ye yükselmesiyle KOİ giderim verimi \%90.63'e yükselmiştir. Faraday yasasına göre, akım yoğunluğundaki artışlar, kurban anot metal iyon konsantrasyonunun ve topak oluşumunun artmasına neden olan elektrot malzemesinin çözünme oranını arttırır. $\mathrm{Bu}$ nedenle kirletici giderimi, artan akım yoğunluğu ile artar.

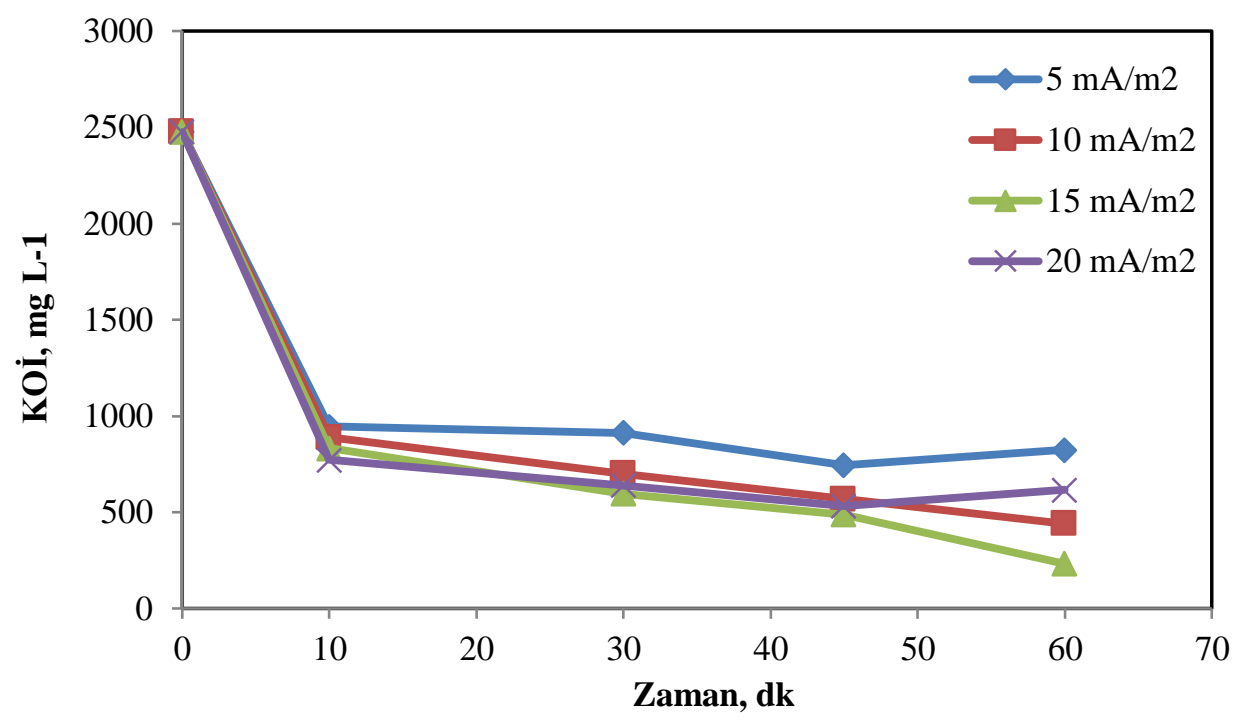

Şekil 2. Farklı akım yoğunluklarında KOİ değerlerinin zamanla değişimi (T:25 ${ }^{\circ} \mathrm{C}, \mathrm{pH}: 7.47$ (doğal), elektrotlar arası mesafe $16 \mathrm{~mm}$ )

Ancak akım yoğunluğunun $20 \mathrm{~mA} \mathrm{~m} \mathrm{~m}^{-2}$ ye yükseltilmesiyle giderim verimi $\% 75$ 'e düşmüştür. Akım yoğunluğundaki artışlar, korozyonu destekleyen ve demir anot elektrotun aktif yüzeyinde oksit tabakası olușturan oksidasyon reaksiyonunun hızını arttırır. $\mathrm{Bu}$ tabakanın oluşması nedeniyle pasivasyon etkileri oluşmuş ve KOİ giderim etkinliğini azaltmıştır. Ayrıca yükseltilmiş akım yoğunluğu kirleticileri flotasyon yoluyla gideren çok sayıda küçük hidrojen kabarcıklarının oluşumunu destekler. Artan akım yoğunluğu, hava kabarcıklarının yoğunluğunu artırır ve flotasyon yoluyla atıksudan kirletici maddenin uzaklaştırılmasını artıran hava kabarcığının boyutunu azaltır. Aynı zamanda artan metal çözünme hızı (koagülant dozu) flokların büyümesini artırır. Eş zamanlı olarak akım yoğunluğundaki artışlar reaktördeki türbülansı yönlendirir, bu nedenle kirleticilerin topaklanma yoluyla uzaklaştırılmasından sorumlu olan parçacıklar (pıhtılaştırıcılar) arasındaki etkileşimi azaltır (Priya ve Jeyanthi, 2019). 


\section{Başlangıç pH'ının Etkisi}

Elektrokoagülasyon işlemi sırasında metalik hidroksitlerin oluşumu atıksuyun pH'ına bağlıdır ve atıksuyun başlangıç $\mathrm{pH}$ 'ı elektrokoagülasyon prosesinin performansinı etkilemektedir (Bener ve ark., 2019).

Deneyler sırasında akım yoğunluğu $15 \mathrm{~mA} \mathrm{~m}^{-2}$,ye, sicaklık $25^{\circ} \mathrm{C}$ ve elektrotlar arası mesafe 16 mm'ye ayarlanmıştır. Atıksuyun başlangıç pH'ının etkisini araştırmak için dört farklı $\mathrm{pH}$ değeri test edilmiştir ve deneysel sonuçlar Şekil 3'de verilmiştir. pH 3, 5, doğal $\mathrm{pH}(7.47)$ ve 10 için giderim verimleri sirasıly $\% 79$, $\% 83, \% 90.63$ ve $\% 80$ olmuştur ve en yüksek KOİ giderim verimi atıksuyun doğal $\mathrm{pH}$ 'ında elde edilmiştir. pH'ın 7.47'ye kadar yükselmesiyle giderim verimi artarken, daha sonra pH'ın 10'a yükselmesiyle giderim verimi düşmüştür. Düşük ve yüksek $\mathrm{pH}$ 'larda, çözünebilir demir hidroksit türleri, demirin Pourbaix diyagramına göre oluşur. Asidik pH'da, katotta protonlar tarafindan üretilen hidroksit iyonlarının çökmesi sonucunda yetersiz demir hidroksit oluşumu nedeniyle nispeten daha düşük giderim verimleri elde edilmiştir.Yüksek bir pH'da, flok oluşumu için uygun olmayan çözünür $\mathrm{Fe}(\mathrm{OH})^{4}$ 'in baskın oluşumu nedeniyle giderim etkinliği azalmıştır. Nötre yakın pH'da, demir komplekslerinin çoğu oluşmuştur ve daha yüksek bir giderim etkinliği elde edilmiştir (Eryuruk ve ark., 2018).
Mevcut çalışmada atıksuyun doğal pH'ında arıtım yapıldığ zaman çıkış suyunun nihai pH'1 7.81 olmuştur. Bu durum, giriş suyunun beslenmesinde ve atık akışlarının boșaltılmasında pH'ı ayarlamak için kimyasal kullanımını ortadan kaldırmaktadır.

\section{Elektrotlar Arası Mesafenin tkisi}

Elektrotlar arasındaki mesafe açısından, kurulum konfigürasyonu, elektrotun gerekli etkili yüzey alanı için oldukça önemlidir ve ayrıca elektrokimyasal hücredeki potansiyel ohmik indirgeme, elektrotlar aras1 mesafe ile orant1lidır (Atashzaban ve ark., 2016).

$\mathrm{Bu}$ çalışmada, bu parametrenin mezbaha atıksularından KOİ giderimi üzerindeki etkisini araştırmak için elektrotlar arasındaki mesafe 4-16 $\mathrm{mm}$ arasında değiștirilmiștir. Deneyler boyunca akım yoğunluğu $15 \mathrm{~mA} \mathrm{~m}{ }^{-2}$, sıcaklık $25{ }^{\circ} \mathrm{C}$ ve başlangıç pH'1 doğal değerinde (7.47) tutulmuştur. Elektrotlar arasındaki mesafenin bir fonksiyonu olarak KOİ giderim verimleri Şekil 4'te sunulmuştur. Şekilden de görüldüğü gibi elektrotlar arası mesafenin arttırılması KOİ giderim verimini arttırmıştır. Elektrotlar arasındaki mesafe arttıça, metal iyonlarının çözünmüş olması nedeniyle KOI giderimi artmıştır (Tevkur, 2019).

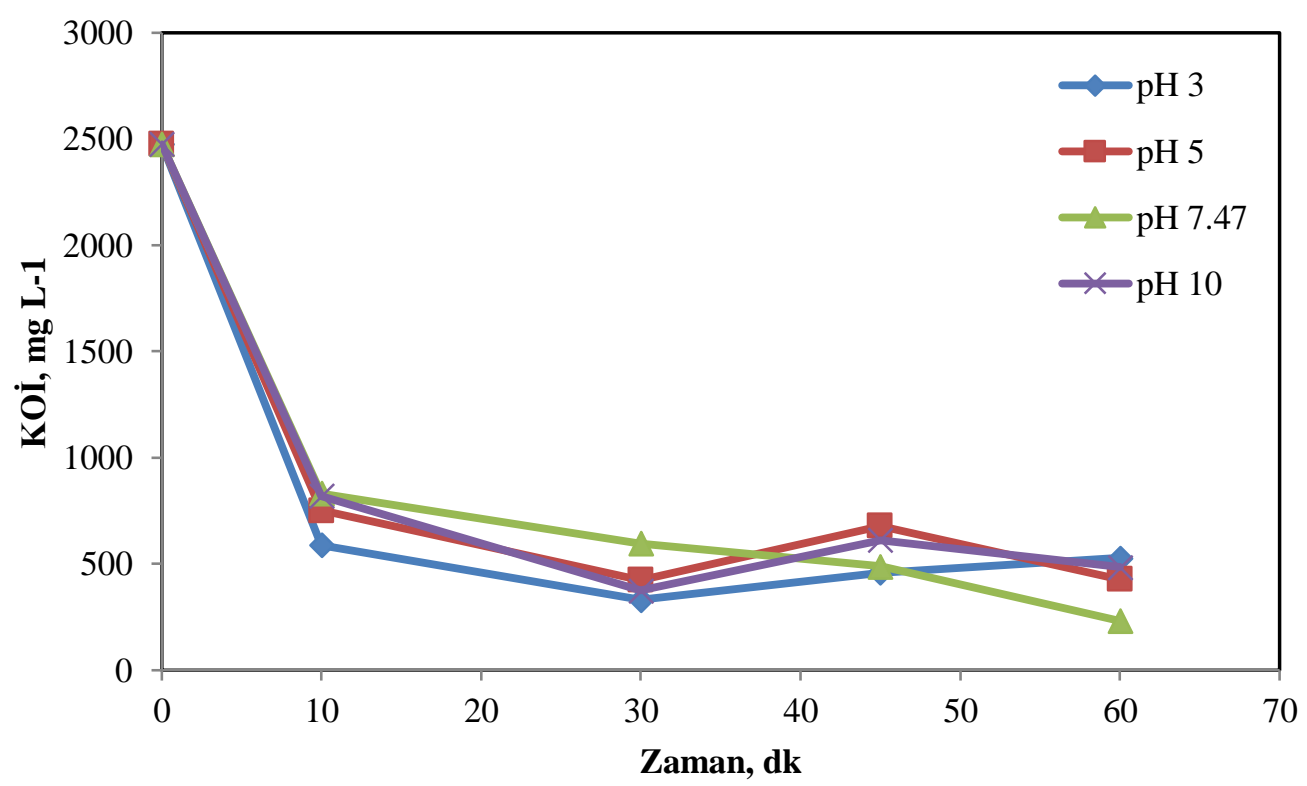

Şekil 3. Farklı pH'larda KOİ değerlerinin zamanla değişimi (T: $25^{\circ} \mathrm{C}$, elektrotlar arası mesafe: $16 \mathrm{~mm}$, akım yoğunluğu: $15 \mathrm{~mA} \mathrm{~m}^{-2}$ ) 


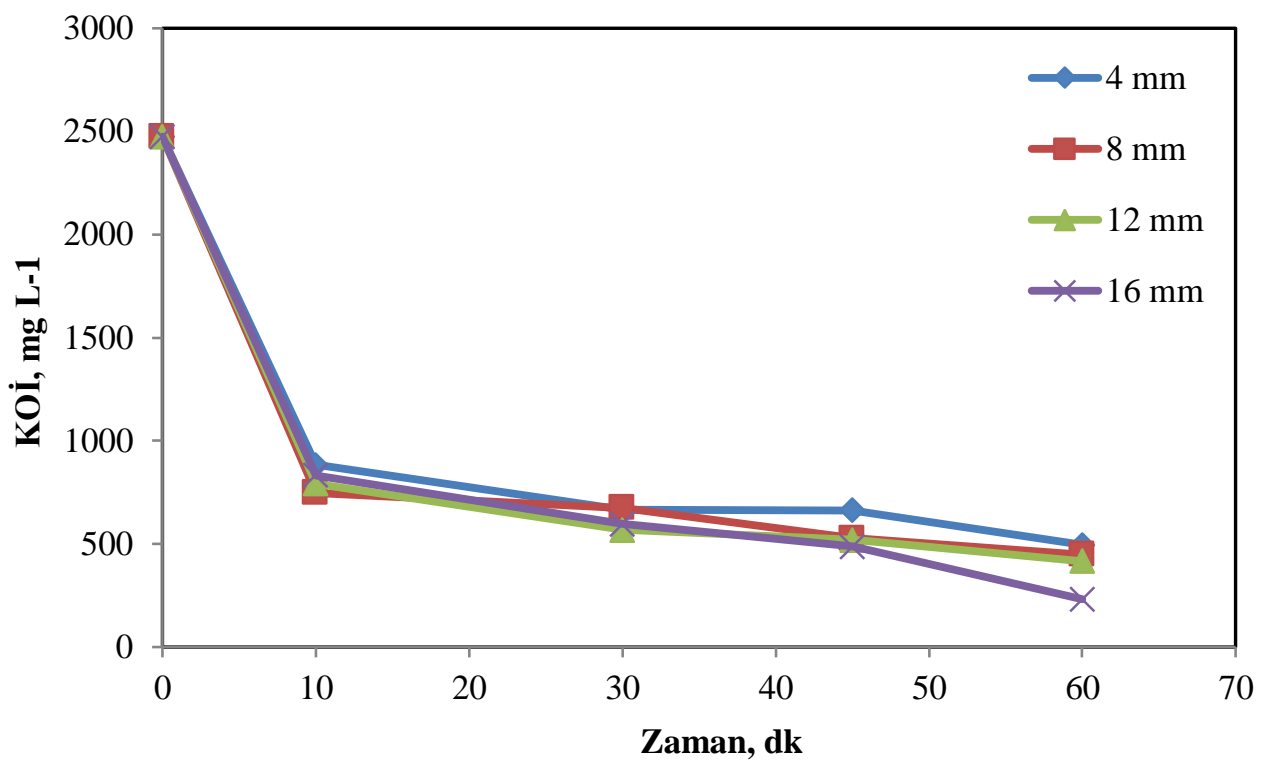

Şekil 4. Elektrotlar arası mesafenin KOİ değerlerinin zamanla değişimine etkisi (T: $25^{\circ} \mathrm{C}, \mathrm{pH}: 7.47$ (doğal), akım yoğunluğu: $15 \mathrm{~mA} \mathrm{~m}^{-2}$ )

\section{Optimum KOİ Giderim Şartları ve İşletme Maliyeti}

Çalışılan elektrokoagülasyon prosesinde elde edilen en yüksek KOİ giderim verimi; 60 dakika işletme süresi, $15 \mathrm{~mA} \mathrm{~m}^{-2}$ akım yoğunluğu, $7.47 \mathrm{pH}$ ve $16 \mathrm{~mm}$ elektrotlar arası mesafe olduğu zaman $\% 90.63$ olarak elde edilmiştir. $\mathrm{Bu}$ şartlarda elde edilen diğer parametrelerin değişimi Tablo 1'de verilmiştir. Elektrokoagülasyon prosesinde ortaya çıkan ana maliyetler enerji ve elektrot tüketiminden kaynaklanmaktadır. $\mathrm{Bu}$ proseste işletme maliyeti giderilen $\mathrm{kg}$ KOİ başına tüketilen enerji miktarı ve elektrot miktarının toplamı olarak ifade edilmiştir (Eşitlik 6). En yüksek KOİ gideriminin elde edildiği şartlarda işletme maliyeti $9.15 \mathrm{TL} \mathrm{kg}^{-1} \mathrm{KOI}^{-1}$ olarak hesaplanmıştır.

Tablo 1. En yüksek KOI giderimi şartlarında ortam parametrelerinin değişimi ve giderim yüzdeleri (T: $25^{\circ} \mathrm{C}, \mathrm{pH}$ : 7.47, elektrotlar arası mesafe: $16 \mathrm{~mm}$, akım yoğunluğu: $15 \mathrm{~mA} \mathrm{~m}^{-2}, \mathrm{t}: 60 \mathrm{dk}$ )

\begin{tabular}{|c|c|c|c|c|}
\hline Parametre & Birim & Ham atıksu & Arıtılmış atıksu & $\begin{array}{l}\text { Giderim } \\
\text { verimi, \% }\end{array}$ \\
\hline $\mathrm{pH}$ & - & 7.47 & 7.81 & - \\
\hline İletkenlik & $\mu \mathrm{s} \mathrm{cm} \mathrm{cm}^{-1}$ & 2131 & 1468 & 31.11 \\
\hline TDS & $\mathrm{mg} \mathrm{L}^{-1}$ & 1521 & 1378 & 9.40 \\
\hline KOİ & $\mathrm{mg} \mathrm{L}^{-1}$ & 2475 & 232 & 90.63 \\
\hline Yağ ve gres & $\mathrm{mg} \mathrm{L}^{-1}$ & 105.40 & 8.20 & 92.22 \\
\hline TKM & $\mathrm{mg} \mathrm{L}^{-1}$ & 2867 & 1636 & 42.94 \\
\hline UKM & $\mathrm{mg} \mathrm{L}^{-1}$ & 1580 & 389 & 75.38 \\
\hline $\mathrm{NH}_{3}-\mathrm{N}$ & $\mathrm{mg} \mathrm{L}^{-1}$ & 48.76 & 23.71 & 51.37 \\
\hline $\mathrm{NO}_{3}^{-}-\mathrm{N}$ & $\mathrm{mg} \mathrm{L}^{-1}$ & 18.90 & 5.35 & 71.69 \\
\hline $\mathrm{NO}_{2}^{-}-\mathrm{N}$ & $\mathrm{mg} \mathrm{L}^{-1}$ & 0.355 & 0.081 & 77.18 \\
\hline TKN & $\mathrm{mg} \mathrm{L}^{-1}$ & 148.80 & 30.30 & 79.64 \\
\hline $\mathrm{PO}_{4}^{-3}$ & $\mathrm{mg} \mathrm{L}^{-1}$ & 263.30 & 8.30 & 96.84 \\
\hline Bulanıklık & NTU & 401 & 0.76 & 99.81 \\
\hline Renk & $\mathrm{m}^{-1}$ & $\begin{array}{l}436 \mathrm{~nm}_{(\mathrm{sarl})}: 460 \\
525 \mathrm{~nm}_{(\mathrm{kurmız})}: 302 \\
620 \mathrm{~nm}_{(\text {mavi) }}: 205\end{array}$ & $\begin{array}{l}436 \mathrm{~nm}_{\text {(sarı) }}: 22.75 \\
525 \mathrm{~nm}_{\text {(krmızl) }}: 7.25 \\
620 \mathrm{~nm}_{\text {(mavi) }}: 3.25\end{array}$ & $\begin{array}{l}95.05 \\
97.60 \\
98.41\end{array}$ \\
\hline
\end{tabular}




\section{SONUÇLAR}

$\mathrm{Bu}$ çalışmada elektrokoagülasyon prosesi kullanılarak mezbaha atıksularının arıtımı gerçekleştirilmiştir. Çalışmada, demir elektrotlu laboratuvar ölçekli kesikli bir reaktörde KOİ giderimi üzerine akım yoğunluğu, $\mathrm{pH}$ ve elektrotlar arası mesafe olmak üzere üç proses değişkeninin etkisi değerlendirilmiştir. En yüksek KOİ gideriminin elde edildiği şartlarda (15 mA m${ }^{-2}$ akım yoğunluğu, 7.47 $\mathrm{pH}$ ve $16 \mathrm{~mm}$ elektrotlar arası mesafe) çıkış KOİ, yağ ve gres ve $\mathrm{pH}$ değerleri sirasıyla $232 \mathrm{mg} \mathrm{L}^{-1}, 8.20 \mathrm{mg}$ $\mathrm{L}^{-1}$ ve 7.81 olmuştur. Bu değerler Su Kirliliği Kontrol Yönetmeliğinde (SKKY, 2004) mezbaha atıksuları için verilmiş olan alıcı ortama deşarj standartlarını sağlamaktadır. Elde edilen sonuçlar elektrokoagülasyon prosesinin mezbaha atıksularının arıtımı için etkili bir yöntem olduğunu doğrulamaktadır.

\section{TEŞEKKÜR}

$\mathrm{Bu}$ çalışma Munzur Üniversitesi Bilimsel Araştırma Projeleri Koordinasyon Birimi tarafindan YLMUB017-08 nolu proje ile desteklenmiştir.

\section{ÇIKAR ÇATIŞMASI BEYANI}

Yazarlar bu çalışmalarında herhangi bir şekilde çıkar çatışması olmadığını beyan ederler.

\section{ARAŞTIRMA VE YAYIN ETİĞİ BEYANI}

Yazarlar bu çalışmalarında, araştırma ve yayın etiğine uyulduğunu beyan ederler.

\section{KAYNAKLAR}

Alfonso-Muniozguren, P., Cotillas, S., Boaventura Rui A.R., Moreira F.C., Lee, J., Vilar, V.J.P., 2020. Single and combined electrochemical oxidation driven processes for the treatment of slaughterhouse wastewater. Journal of Cleaner Production, 270:121858.

APHA, 2005. Standard methods for the examination of water and wastewater, 21st ed. American public health association, American Water Works Association, Water Environment Federation, Washington, DC, USA.

Atashzaban, Z., Seidmohammadi, A., Nematollahi, D., Azarian, G., Shayesteh, O.H., Rahmani, A.R., 2016. The efficiency of electrocoagulation and electroflotation processes for removal of polyvinyl acetate from synthetic effluent, Journal of Environmental Health Science and Engineering, 3(2):74-69.
Bayar, S., Yıldız, Y.Ş., Yılmaz, A.E., İrdemez, Ş., 2011. The effect of stirring speed and current density on removal efficiency of poultry slaughterhouse wastewater by electrocoagulation method. Desalination, 280:103-107.

Bayramoglu, M., Kobya, M., Eyvaz, M., Senturk, E., 2006. Technical and economic analysis of electrocoagulation for the treatment of poultry slaughterhouse wastewater. Separation and Purification Technology, 51:404-408.

Bener, S., Bulca, Ö., Palas, B., Tekin, G., Atalay, S., Ersöz, G., 2019. Electrocoagulation process for the treatment of real textile wastewater: Effect of operative conditions on the organic carbon removal and kinetic study. Process Safety and Environmental Protection, 129:47-54.

Canizares, P., Martinez, F., Rodrigo, M.A., Jimenez, C., Saez, C., Lobato, J., 2008. Modelling of wastewater electrocoagulation processes Part II: Application to dye-polluted wastewaters and oil-inwater emulsions. Separation and Purification Technology, 60:147-154.

Daneshvar, N., Khataee, A.R., Ghadim, A.R., Rasoulifard, M.H., 2007. Decolorization of C.I. Acid yellow 23 solution by electrocoagulation process: investigation of operational parameters and evaluation of specific electrical energy consumption (SEEC). Journal of Hazardous Material, 148(3):566572.

Eryuruk, K., Tezcan Un, U., Ogutveren, U.B., 2018. Electrochemical treatment of wastewaters from poultry slaughtering and processing by using iron electrodes. Journal of Cleaner Production, 172: 1089-1095.

Fajardo, A.S., Rodrigues, R.F., Martins, R.C., Castro, L.M., Quinta-Ferreira, R.M., 2015. Phenolic wastewaters treatment by electrocoagulation process using $\mathrm{Zn}$ anode. Chemical Engineering Journal, 275:331-341.

Nery, V.D., de Nardi, I.R., Damianovic, M.H.R.Z., Pozzi, E., A.K. Amorimd, B., Zaiat, M., 2007. Long-term operating performance of a poultry slaughterhouse wastewater treatment plant, Resources, Conservation \& Recycling, 50(1):102114.

Ozturk, D., Yilmaz, A.E., 2019. Treatment of slaughterhouse wastewater with the electrochemical oxidation process: Role of operating parameters on treatment efficiency and energy consumption. Journal of Water Process Engineering, 31:100834.

Palahouane, B., Drouiche, N., Aoud, S., Bensadok, K., 2015. Cost-effective electrocoagulation process for the remediation of fluoride from pretreated photovoltaic wastewater. Journal of Industrial and Engineering Chemistry, 22:127-131. 
Priya, M., Jeyanthi, J., 2019. Removal of COD, oil and grease from automobile wash water effluent using electrocoagulation technique. Microchemical Journal, 150:104070.

Rajakumar, R., Meenambal, T., Saravanan, P.M., Ananthanarayanan, P., 2012. Treatment of poultry slaughterhouse wastewater in hybrid upflow anaerobic sludge blanket reactor packed with pleated polyvinyl chloride rings. Bioresource Technology, 103(1):116-122.

Safwat, M.S., 2020. Treatment of real printing wastewater using electrocoagulation process with titanium and zinc electrodes. Journal of Water Process Engineering, 34:101137.

Su Kirliliği ve Kontrolü Yönetmeliği, 2004. 31.12.2004 tarih ve 25867 sayıl1 Resmi Gazete.

Tevkur, S., 2019. Mezbaha atıksularının elektrokoagülasyon prosesi kullanılarak arıtılması, Yüksek Lisans Tezi, Munzur Üniversitesi Fen Bilimleri Enstitüsü, Tunceli. 